\title{
Absent left atrioventricular connection with right atrium connected to morphologically left ventricular chamber, rudimentary right venüricular chamber, and ventriculoarterial discordance Problem of mitral versus tricuspid atresia
}

\author{
ANGELO RESTIVO, SIEW YEN HO, ROBERT H ANDERSON, HUGH CAMERON, \\ JAMES L WILKINSON \\ From the Department of Paediatrics, Cardiothoracic Institute, Brompton Hospital, London; the Department of \\ Pathology, Birmingham Children's Hospital, Birmingham; and Department of Paediatric Cardiology, Royal \\ Liverpool Children's Hospital, Liverpool
}

SUMMARY Four cases of absent left atrioventricular connection are reported. The observations from these cases have been used to emphasise problems concerning the use of the confusing terms "tricuspid" and "mitral" atresia to describe such hearts. One of the four cases represents a very uncommon condition since the rudimentary chamber was contralateral to the side of the absent atrioventricular connection. The morphology of the conduction system has been elucidated with emphasis given to the surgical implications of these anomalies.

Atrioventricular valve atresia has become the subject of increased interest since the development of innovative surgical treatment. ${ }^{1}$ Only recently, however, has the anatomy of these syndromes been clarified with emphasis to the differentiation of an absent atrioventricular connection and an imperforate atrioventricular valve. ${ }^{2}$ It has also been pointed out that when one atrioventricular connection is absent, the morphology of the patent atrioventricular valve is highly variable and poorly identifiable. Consequently it has been suggested that it is more accurate to distinguish these cases as absent right or left atrioventricular connection rather than tricuspid and mitral atresia. ${ }^{2}$ More recently, however, the advisability of this concept has been questioned. ${ }^{3}$ In the light of this correspondence, we report here four pertinent cases with absent left atrioventricular connection. The findings in these hearts strongly support the remarks of one of us in an earlier paper. ${ }^{4}$ All the hearts had main ventricular chambers of left ventricular type. Two cases had the rudimentary right ventricular chamber on the same

RHA and SYH are supported by the British Heart Foundation together with the Joseph Levy Foundation.

Accepted for publication 19 May 1982 side of the absent connection, the usual pattern. One case, in contrast, had the rudimentary chamber on the opposite side to the absent atrioventricular connection. ${ }^{56}$ The final case is even more fascinating since the rudimentary right ventricular chamber was more or less directly anterior.

\section{Case reports}

CASE 1

The heart was situated in the left hemithorax, with the apex to the left. There was a left aortic arch (Fig. 1a). Atrial situs solitus was present with normal venous connections. The right atrium was enlarged. The left atrium showed an accessory superior chamber into which four pulmonary veins drained. It was obstructed at its junction with the main atrial chamber, which received two large pulmonary veins. The left atrial floor was completely muscular, having no connection with the ventricular mass (Fig. 1b). The atrial septum showed a patent foramen ovale. The ventricular mass was largely made up of a left ventricular chamber. It was connected with the right atrium through an atrioventricular valve of uncertain morphology (Fig. 1c) Two leaflets were tethered by large 


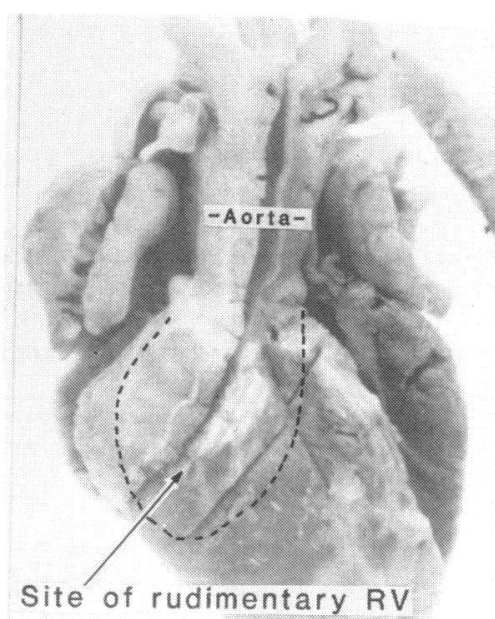

a)

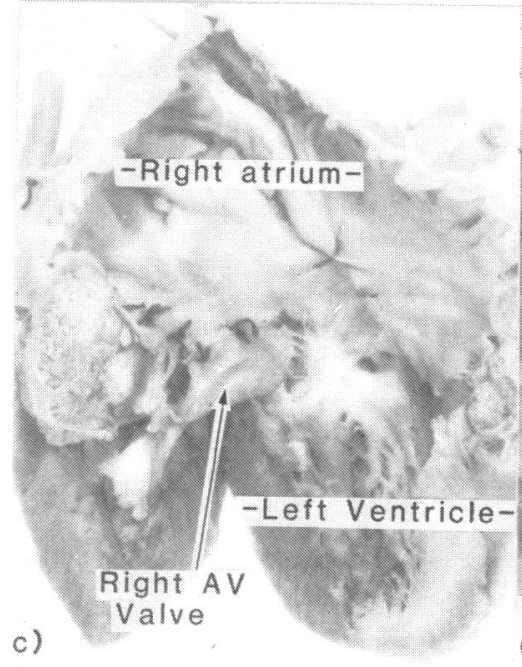

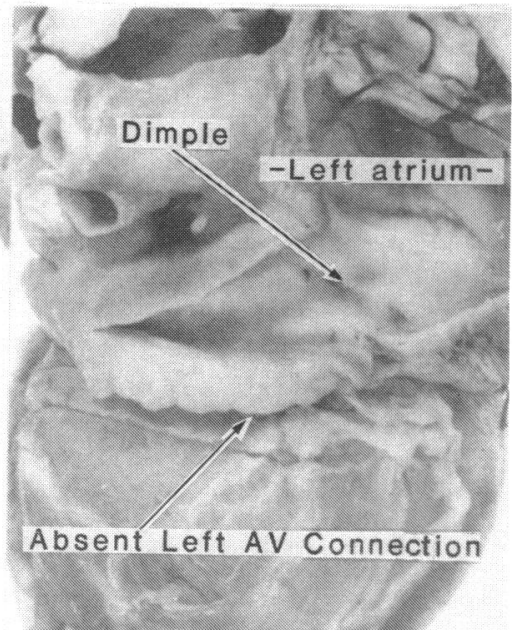

b)

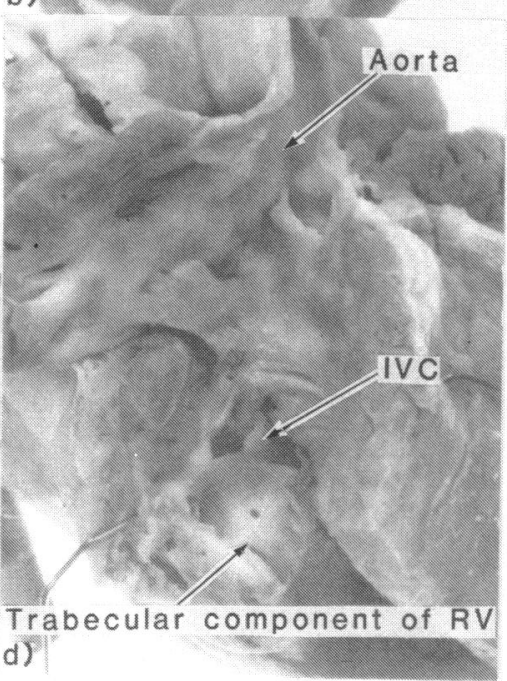

Fig. 1 The cardiac morphology in case 1. (a) The anterior view of the heart. The dotted line shows the position of the rudimentary right ventricular chamber. (b) The absent left atrioventricular connection. (c) The right atrium connected to a left ventricular chamber. (d) The opened rudimentary right ventricular chamber, the right atrioventricular $(A V)$ valve being seen covering over the interventricular communication (IVC). anterior and posterior papillary muscles. The interventricular communication, which looked obstructed since it was covered by the atrioventricular valve mural leaflet, led to a hypoplastic right sided and anterior rudimentary chamber of right ventricular type which showed a prominent trabecular portion and extremely short infundibular segment (Fig. 1d). The aorta arose from the rudimentary chamber, being anterior and to the right of the pulmonary trunk which arose from the main left ventricular chamber. The pulmonary valve was in fibrous continuity with the solitary atrioventricular valve. The ascending aorta and the arch appeared moderately hypoplastic. A persistent ductus arteriosus was present.

Fig. 2 shows a diagrammatic representation of the conduction system as judged from inspection of the heart. The atrioventricular bundle was not in direct relation with the posterior pulmonary outflow tract.

\section{CASE 2}

The aortic arch and cardiac apex were to the left (Fig. 3a). Atrial situs solitus with normal venous connections was found. The left atrium had no connection with the ventricular mass. A patent foramen ovale was present. The main left ventricular chamber was connected with the right atrium through an atrioventricular valve of atypical morphology which showed three leaflets (Fig. 3b). A third papillary muscle was attached to the trabecular septum. The interventricular communication was displaced leftwards, leading to a rudimentary chamber of right ventricular type which was mostly on the left (Figs 3a, 3c). The 


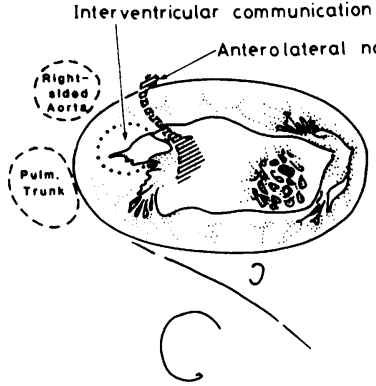

Surgeon's view through right atrioventricular valve

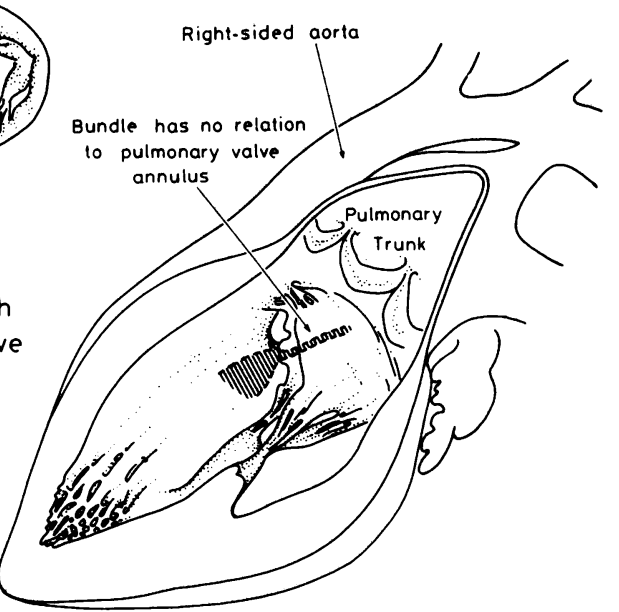

Morphologist's view through left ventricular chamber

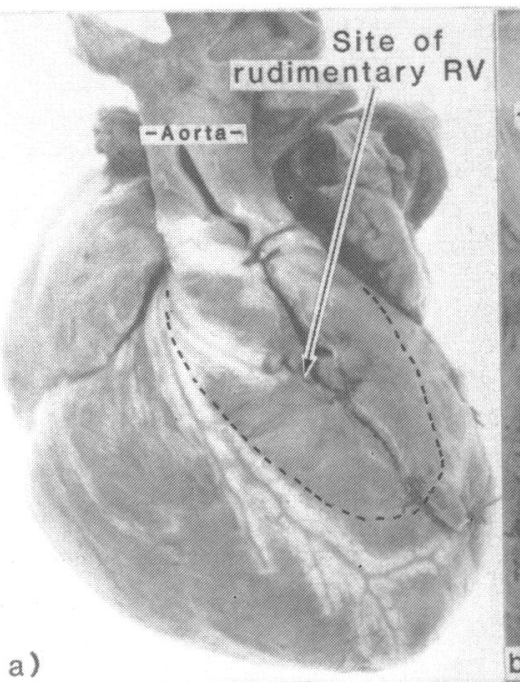

a)

b)

\section{-Left ventricle-}

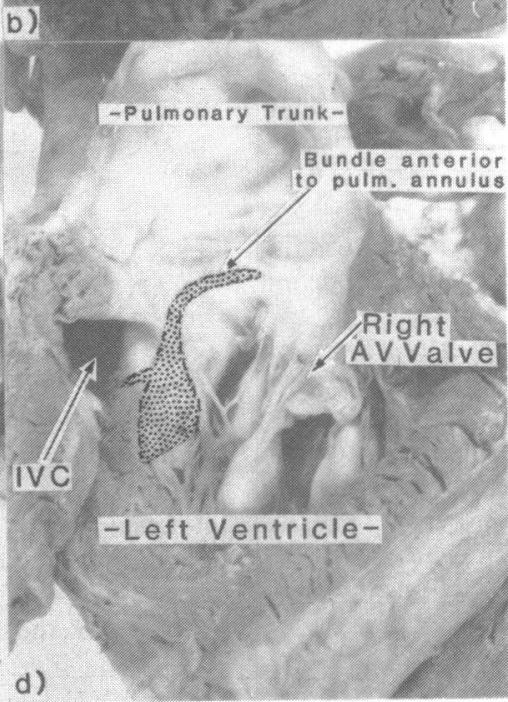

Fig. 2 A representation of the conduction tissue disposition in case 1 . The main drawing shows the site of the atrioventricular conduction axis as would be seen through an incision in the left side of the left ventricular chamber (compare with Fig. 3d). The inset shows the course of the bundle relative to the right atrioventricular and pulmonary valves as would be seen by the surgeon approaching via the right atrium.

Fig. 3 The cardiac morphology of case 2. (a) The anterior view of the heart. Despite the left sided position of the rudimentary right ventricular chamber (dotted lines) the aorta is to the right of the pulmonary trunk. (b) The right atrioventricular valve connecting right atrium to a left ventricular chamber. (c) The opened rudimentary right ventricular chamber. (d) The main left ventricular chamber opened through a left sided incision. The site of the conduction tissues has been superimposed (compare with Fig. 2). 

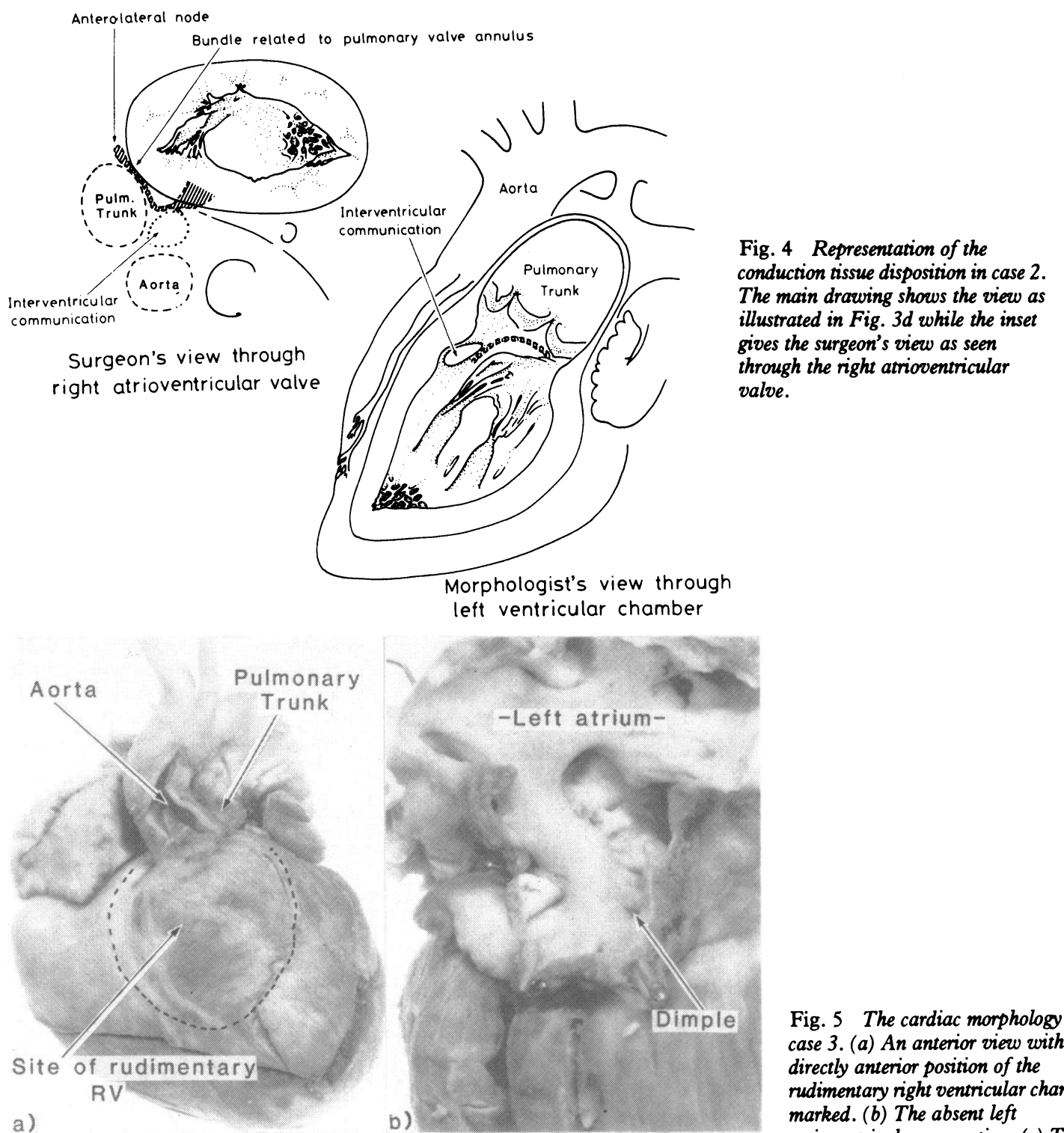

a)
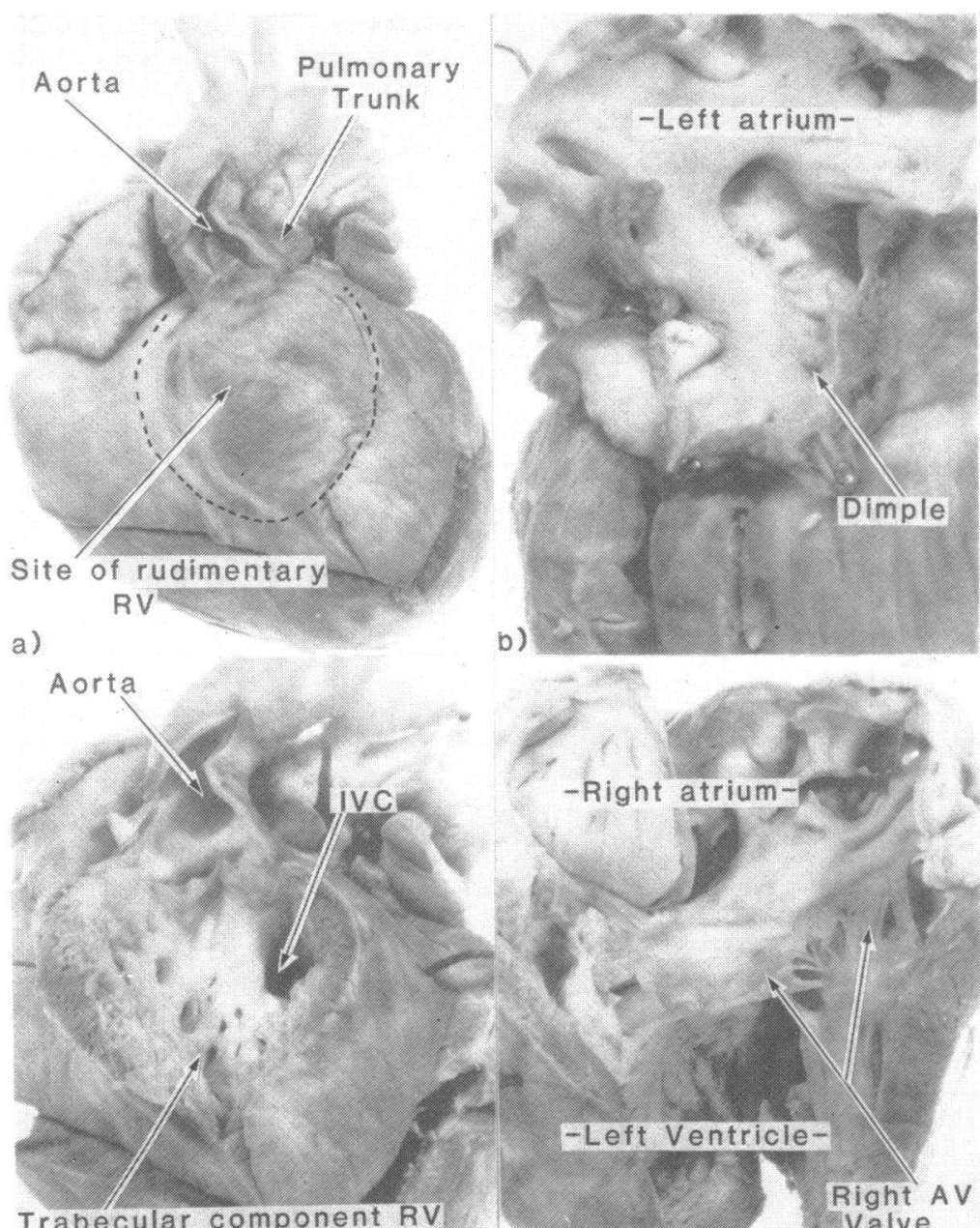

Fig. 5 The cardiac morphology of case 3. (a) An anterior view with the directly anterior position of the rudimentary right ventricular chamber marked. (b) The absent left atrioventricular connection. (c) The opened rudimentary chamber. (d) The morphology of the right atrioventricular valve.

c)

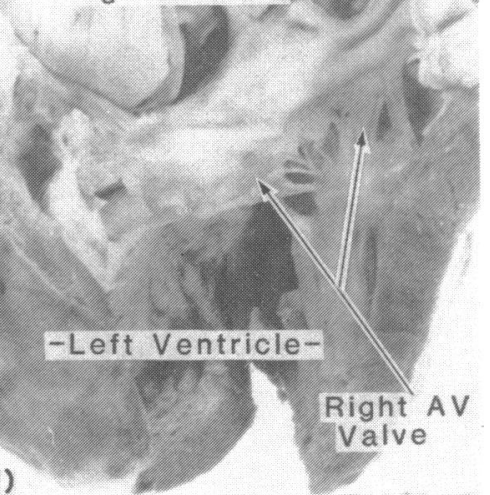

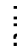




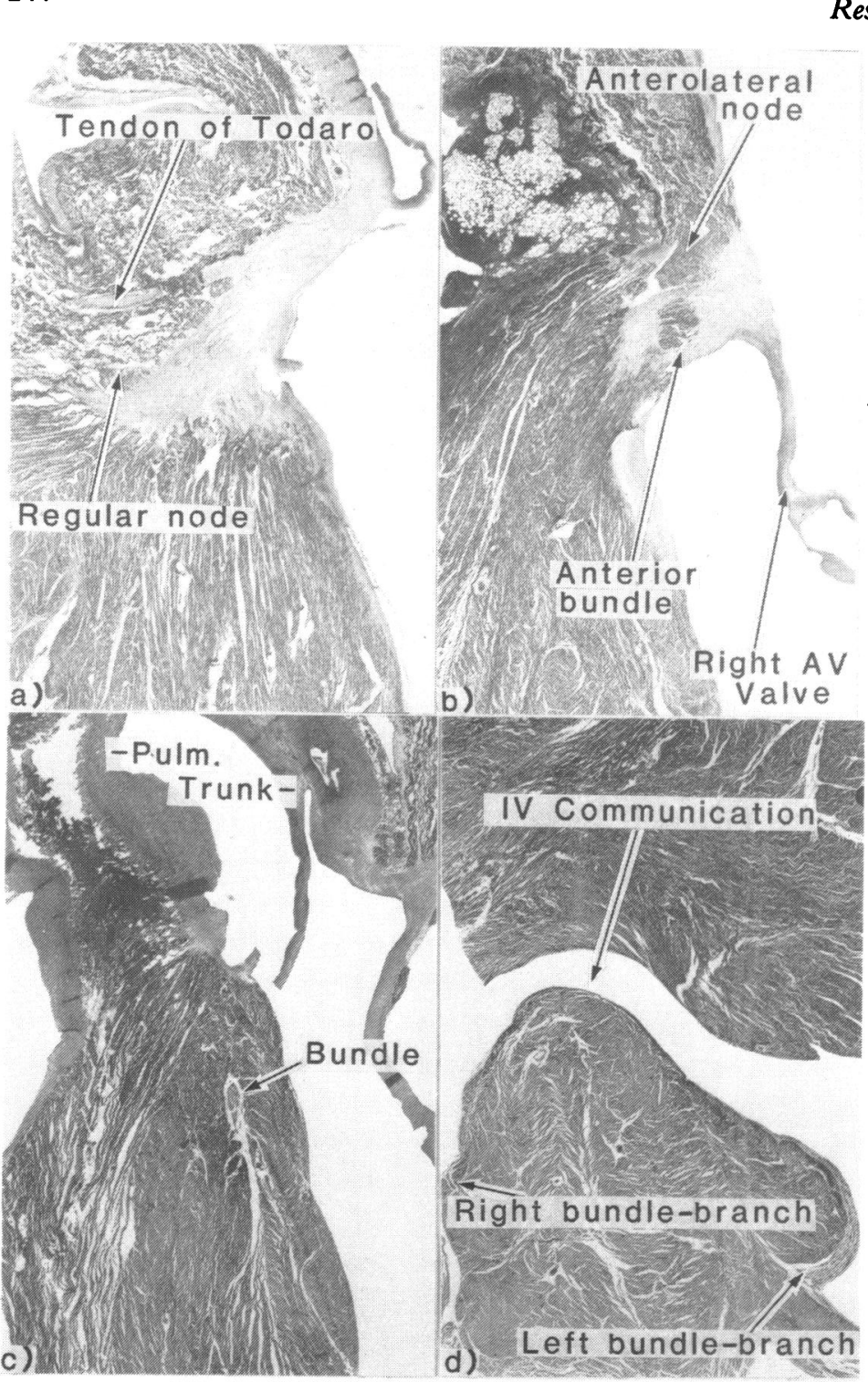

Fig. 6 The conduction tissues from case 4. (a) The regular atrioventricular node at the apex of the triangle of Koch which makes no connection with the ventricular conduction tissues. (b) The anterolateral node giving rise to the penetrating bundle. (c) The bundle running intramyocardially around the anterior quadrant of the pulmonary trunk. (d) The bundle-branches to either side of the interventricular septum.

rudimentary chamber showed a prominent trabecular portion and a very short infundibular segment, giving origin to a normally sized aorta, there being no obstruction of the interventricular communication (Fig. 3c). Despite the leftward position of the rudimentary chamber, the aorta was found to be on the right and anterior to the pulmonary trunk (Fig. 3c). The pulmonary trunk arose from the main left ventricular chamber in fibrous continuity with the patent atrioventricular valve (Fig. 3b). A ductus arteriosus was also present in this case.

In Fig. 4 the course of the conduction tissue is shown as judged from the gross examination of the heart. Note that the non-branching bundle encircles the subpulmonary outflow tract.

\section{CASE 3}

There was left sided position of the aortic arch and cardiac apex (Fig. 5a). Atrial situs solitus with normal venous drainage was encountered. The left atrioventricular connection was absent (Fig. 5b). The atrial septum showed evidence of balloon septostomy. The right atrium communicated with the main left ventricular chamber through an atrioventricular valve 
which showed two leaflets (Fig. 5c). Anterior and posterior papillary muscles were present. A good sized interventricular communication was found to be anterior and to the left of the ventricular mass leading to a rudimentary chamber of right ventricular type which showed a prominent trabecular component and very short infundibular segment (Fig. 5d). The rudimentary chamber was more or less anterior in relation to the main chamber; the rudimentary trabecular component, however, was unequivocally on the right. The aorta arose from the rudimentary chamber and was anterior and to the right of the pulmonary trunk (Fig. 5a). The pulmonary trunk, taking origin from the main chamber, was in fibrous continuity with the patent atrioventricular valve. Both great arteries were of normal size and a persistent ductus arteriosus was present.

The conduction tissue disposition was as illustrated in Fig. 4.

\section{CASE 4}

The aortic arch and cardiac apex were to the left. Atrial situs solitus with normal venous connections was present. Absence of the left atrioventricular connection was found, with a patent foramen ovale on the atrial septal surface. The right atrium connected with the main left ventricular type chamber through an atrioventricular valve which was of mitral morphology, having paired papillary muscles. The interventricular communication was to the left of the ventricular mass and was somewhat restrictive. It led to a left sided rudimentary chamber of right ventricular type which showed the same prominent trabecular component and a very short infundibular segment as encountered in the three previous cases. The aorta, arising from the rudimentary chamber, was anterior and to the left of the pulmonary trunk. Aortic arch and isthmal hypoplasia were found. The pulmonary trunk arose from the main chamber with the atrioventricular valve. Persistent ductus arteriosus was also present.

In this case the entire right atrioventricular junction was sectioned to show the disposition of the conduction tissues. The regular node in the atrial septum made no contact with the ventricular myocardial tissues, being a blind-ending structure (Fig. 6a). Instead, an anomalous anterolateral node was found (Fig. 6b) which gave rise to a penetrating atrioventricular bundle. This penetrated to the right of the pulmonary trunk. A long non-branching bundle (Fig. 6c) then encircled the anterior quadrant of the pulmonary valve before descending into the right margin of the interventricular septum, where it branched on its left ventricular aspect well below the septal crest (Fig. 6d). A right bundle-branch then penetrated through the septum into the rudimentary right ven- tricular chamber while the left bundle-branch ramified on the left ventricular surface. The overall distribution of atrioventricular conduction tissue was as shown in Fig. 4.

\section{Discussion}

In the past it has been customary to classify the atrioventricular valve atresias simply as tricuspid atresia and mitral atresia. Only recently has the full anatomy of the lesions been discussed with regard to the clinical ability to differentiate an absent atrioventricular connection from an imperforate atrioventricular connection. ${ }^{2}$ In the light of these findings, it has been suggested that, when one atrioventricular connection is absent, it is preferable to distinguish absence of the right sided and left sided connections rather than nominating the conditions as tricuspid or mitral atresia. This is because, since the essence of the anomaly is absence of the atrioventricular connection, it can never be known with certainty whether, had the connection developed, it would have been guarded by a mitral or a tricuspid valve.

In the hearts herein described, the right atrium communicated always with a left ventricular chamber and always there was ventriculoarterial discordance. The difference in the four cases related only to the position of the rudimentary right ventricular chamber. In two cases the chamber was left sided, as usually described in this entity, but in one it was right sided and in the other it was directly anterior. All this is vital information in the light of the recent suggestion by Gittenberger-de Groot and Wenink ${ }^{3}$ that all hearts with valve atresia should be distinguished as having mitral or tricuspid atresia according to the ventricular architecture present. They indicated that ventricular architecture could be deduced from knowing the ventricular relations, and then from this information the nature of the atretic valve could be inferred. If we apply this process to our cases, then presumably a diagnosis of "mitral atresia" would be made in the case with right sided rudimentary chamber and "tricuspid atresia" in the cases with left sided rudimentary chamber. But what of the case with directly anterior chamber? Furthermore, if we examine the case with right sided rudimentary chamber (presumed d-bulboventricular loop), one would expect the solitary atrioventricular valve to be of tricuspid morphology. Instead, we find it to be more reminiscent of mitral morphology. Conversely, considering the second case with a left sided rudimentary chamber (presumed 1-loop), a solitary mitral valve would be expected. Surprisingly, the valve present is reminiscent of a tricuspid valve.

What this shows is that the conclusion that one can categorise all valve atresias as mitral or tricuspid from inferential evidence concerning ventricular architec- 
ture is palpably incorrect. In the cases we studied, architecture could certainly not be predicted with accuracy from knowledge of the ventricular relations. It may be possible to make a more accurate judgement knowing the morphology of the atrioventricular valve present, but this information is unlikely to be available to the clinician. Thus, the concept offered by Gittenberger-de Groot and Wenink ${ }^{3}$ may be of value to the morphogeneticist, but is unlikely to be of great help to the clinician, since it is not based upon morphological features as observed by the clinician. We submit that it is far more accurate, more comprehensive, and more useful simply to describe absence (or atresia) of the right or left atrioventricular connection and then to describe the chamber combinations present. This gives the information required by the clinician, and at the same time gives all the evidence required by the morphogeneticist to make deductions concerning the nature of the atretic connection if this is so desired.

From this discussion, it can be seen that in no way do we deny the value of the looping concept promoted by Van Praagh et al. ${ }^{7}$ as a mechanism for the understanding of congenital heart disease. Indeed, Weinberg, working with Van Praagh and others, ${ }^{8}$ has shown more recently how it is essential to describe the loop (ventricular architecture) in those rare cases where it is incongruous for a given atrial situs and atrioventricular connection. Our own group' has further emphasised the need for describing the ventricular architecture in hearts with ambiguous atrioventricular connection. But the feature of all these hearts (that is those with biventricular atrioventricular connections) is that the architecture can be readily identified in terms of the imaginary placement of the palmar surface of the observer's hand on the septal surface of the morphologically right ventricle with the thumb in the inlet, the wrist in the trabecular component, and the fingers in the outlet. ${ }^{10}$ In this way, right hand (typical for the normal) and left hand (typical for "ventricular inversion") patterns can be easily appreciated. It is much harder to determine ventricular architecture when the atria connect to only one ventricular chamber (univentricular atrioventricular connection), particularly when the ventricle is of left ventricular or indeterminate morphology. This is because the inlets in such hearts are either connected to the same ventricle, or else one inlet is absent. It is not therefore possible to "anchor one's thumb" when trying to "place the imaginary hand" on the septal surface of the morphologically right ventricular chamber (or, in the indeterminate hearts, to find a septum). Because of this we find it difficult to apply the "loop convention" in hearts with univentricular atrioventricular connection such as presently described. Moreover, we can see neither a need nor any relevance, from the clinician's or surgeon's view point, to attempt so to identify the "loop' or the imagined morphology of the absent valve. The first $\stackrel{?}{+}$ case presently described deserves particular comment $\bar{C}$ since it represents a very uncommon condition. Usu- 흠 ally absence of one atrioventricular connection is $\frac{\bar{C}}{7}$ associated with presence of the rudimentary ventricu- $\mathbb{Q}$ lar chamber on the same side as the absent connec- \& tion. Two cases, however, were reported by Quero, ${ }^{5} 6$ with the rudimentary chamber on the opposite side to the absent connection. Subsequently a few additional $\overrightarrow{\vec{J}}$ cases have been described ${ }^{1-13}$ and angiocardio- $\sigma^{2}$ graphic documentation has been reported. ${ }^{14}$ In his original report, Quero indicated that the right sided position of the rudimentary right ventricular chamber $\omega$ pointed to the existence of mitral atresia, again using iv the loop to predict the nature of absent connection. He then suggested that this was most unusual, since 을 with mitral atresia it would be expected for the left ventricular chamber to be hypoplastic and the right $\mathscr{D}$ ventricular chamber to be the main ventricular $O$ chamber. He expressed this in terms of normal development, rather than hypoplasia, of the topographically homologous ventricle. At that time, however, the distinction had not been made between $\vec{\emptyset}$ atrioventricular valve atresias with biventricular and ! univentricular atrioventricular connections. If the cases described had possessed imperforate valve membranes, Quero's comments ${ }^{5}{ }^{6}$ would be entirely appropriate. But in fact the cases had absence of an atrioventricular connection. When an atrioventricular connection is absent and the other atrium connects to a main ventricular chamber, the relation of the $\frac{9}{3}$ rudimentary ventricular chamber is an independent factor. So, when the left connection is absent and the right atrium connects to a left ventricular chamber,

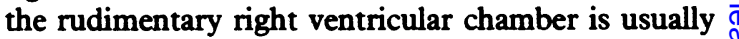
left sided, but as we have seen may be right sided or even directly anterior. When the right atrioventricular connection is absent with similar chamber connections, then usually the rudimentary right ventricle is $O$ right sided, but it may be directly anterior or even to the left. In hearts with univentricular atrioventricular 윽 connection to a left ventricular chamber, it has been $D$ emphasised that, though there is a basic disposition of the atrioventricular conduction system, the precise $N$ course of the non-branching atrioventricular bundle within the ventricles is dependent upon the position $N$ of the rudimentary chamber. ${ }^{15-17}$ The findings $\omega$ encountered in the cases here reported further sup- $\mathcal{O}$ port these remarks. In the first case with right sidedo rudimentary chamber there was an anterior node from $\mathbb{\Phi}$ which a very short bundle arose going down immedi- $?$ ately along the main chamber aspect of the trabecular septum. ${ }^{18}$ In contrast, in the cases with left sided $\stackrel{\vec{\Phi}}{\Phi}$ rudimentary chambers, there was an anterior node, in $\stackrel{\mathbb{P}}{\stackrel{D}{\circ}}$ 
the same position as in case 1 , from which an elongated atrioventricular bundle coursed towards the trabecular septum in close proximity to the posterior pulmonary outflow tract.

These morphological features are of considerable surgical significance. If surgical "correction" is to be attempted in hearts such as these, it will probably be done using a Fontan type procedure. The position of the node will not be a major feature, since always it will be necessary to preserve the right atrioventricular orifice. It is the relation of the conduction tissues to the interventricular communication which is paramount. If there is ventriculoarterial discordance, as is usually the case, it may be necessary to enlarge this communication. If there is ventriculoarterial concordance, a rare happening, ${ }^{5}$ it will be necessary to close the communication if an atrioventricular conduit is to be constructed. ${ }^{19}$ Whichever option is attempted, it must be known that the branching bundle is carried on the left ventricular aspect of the septum away from the septal crest, and that the non-branching bundle descends on to the right margin of the foramen. The rim of the foramen formed by the outlet septum never harbours conduction tissue, and the left margin is also a safe area for resection. These rules hold good whatever the position of the rudimentary right ventricular chamber (Fig. 7). It must be emphasised, however, that we speak of the right and left margins of the interventricular communication relative to its anatomical position. These margins may not always be perceived as being in right sided or left sided position, this depending entirely upon the approach taken by the surgeon.

Finally, the rare occurrence of ventriculoarterial concordance $^{5}$ in these anomalies is worthy of emphasis. This arrangement permits the pulmonary venous blood to be switched into the main left ventricular chamber via an intra-atrial baffle. The rudimentary chamber can then be opened and the interventricular communication closed, a valved conduit being placed between the right atrium and the rudimentary right ventricular chamber. This procedure, which represents a modification of the Fontan operation, has been successfully performed in one case. ${ }^{19}$ The reason for incorporating the rudimentary chamber into the pulmonary circuit is the possibility of growth and development of the chamber. Such a modified Fontan procedure could be performed even in cases in which the rudimentary chamber is left sided, providing there is ventriculoarterial concordance. If ventriculoarterial discordance is present, however, as in the cases here reported, a baffle procedure and the classical atriopulmonary Fontan bypass would be the only possible option other than combining an atrioventricular bypass with an arterial switch procedure. ${ }^{20}$
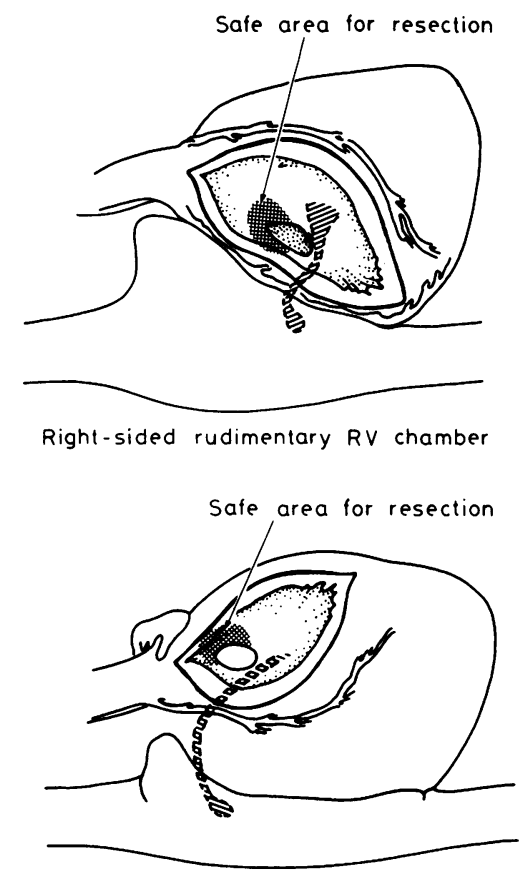

Left-sided rudimentary RV chamber

Fig. 7 Diagram illustrating the vital relation of the atrioventricular conduction axis to the interventricular communication as seen by the surgeon approaching through the rudimentary right ventricular chamber. Note that the position of the rudimentary chamber does not alter the basic disposition of the conduction axis, and that the safe area for widening the communication is the same in both arrangements.

\section{References}

1 Fontan F, Baudet E. Surgical repair of tricuspid atresia. Thorax 1971; 26: 240-8.

2 Anderson RH, Wilkinson JL, Gerlis LM, Smith A, Becker AE. Atresia of the right atrioventricular orifice. Br Heart F 1977; 39: 414-28.

3 Gittenberger-de Groot AC, Wenink ACG. Atresia of left atrioventricular orifice (letter). Br Heart $\mathcal{f}$ 1982; 47: $107-8$.

4 Thiene G, Daliento L, Frescura C, De Tommasi M, Macartney FJ, Anderson RH. Atresia of left atrioventricular orifice. Anatomical investigation in 62 cases. $\mathrm{Br}$ Heart f 1981; 45: 393-401.

5 Quero M. Atresia of the left atrioventricular orifice associated with a Holmes heart. Circulation 1970; 42: $739-44$.

6 Quero M. Coexistence of single ventricle with atresia of one atrioventricular orifice. Circulation 1972; 46: 794-8.

7 Van Praagh R, Van Praagh S, Vlad P, Keith JD. Anatomic types of congenital dextrocardia. Diagnostic 
and embryologic implications. Am $\mathcal{f}$ Cardiol 1964; 13: 510-31.

8 Weinberg PM, Van Praagh R, Wagner HR, Cuaso CC. New form of criss-cross atrioventricular relation: an expanded view of the meaning of D and L-loops (abstract) In: Book of World Congress of Paediatric Cardiology, London 1980. 1980: 319.

9 De Tommasi SM, Daliento L, Ho SY, Macartney FJ, Anderson RH. Analysis of atrioventricular junction, ventricular mass, and ventriculoarterial junction in 43 specimens with atrial isomerism. $\mathrm{Br}$ Heart $\mathrm{f} \mathrm{1981;} \mathrm{45:}$ 236-47.

10 Van Praagh S, LaCorte M, Fellows KE, et al. Superioinferior ventricles: anatomic and angiographic findings in ten postmortem cases. In: Van Praagh R, Takao A, eds. Etiology and morphogenesis of congenital heart disease. Mount Kisco, New York: Futura, 1980: 317-78.

11 Cabrera A, Azcuna JI, Bilbao F. Single primitive ventricle with D-transposition of the great vessels and atresia of the left A-V valve. Am Heart $\mathcal{F}$ 1974; 88: 225-8.

12 Otero Coto E, Caffarena Raggio JM, Malo P, Sainz C, Aparisi R, Gomez-Ullate JM. Single primitive ventricle with normally related great arteries and atresia of the left A-V valve. Thorax 1978; 33: 619-24.

13 Ando M, Satomi G, Takao A. Atresia of tricuspid or mitral orifice: anatomic spectrum and morphogenetic hypothesis. In: Van Praagh R, Takao A, eds. Etiology and morphogenesis of congenital heart disease. Mount Kisco, New York: Futura, 1980: 421-88.

14 Macartney FJ, Partridge JB, Scott O, Deverall PB.
Common or single ventricle. An angiographic and hemodynamic study of 42 patients. Circulation 1976; 53: 543-54.

15 Anderson RH, Arnold R, Thapar MK, Jones RS, Hamilton DI. Cardiac specialized tissues in hearts with an apparently single ventricular chamber. (Double inlet left ventricle.) Am F Cardiol 1974; 33: 95-106.

16 Becker AE, Wilkinson JL, Anderson RH. Atrioventricular conduction tissues in univentricular hearts of left ventricular type. Herz 1979; 4: 166-75.

17 Essed CE, Ho SY, Shinebourne EA, Joseph MC, Anderson RH. Further observations on conduction tissues in univentricular hearts—surgical implications. Eur Heart $\mathcal{f}$ 1981; 2: 87-96.

18 Wenink ACG. The conducting tissues in primitive ventricle with outlet chamber: two different possibilities. $\mathcal{F}$ Thorac Cardiovasc Surg 1978; 75: 747-53.

19 Shore D, Jones O, Rigby ML, Anderson RH, Lincoln C. Atresia of left atrioventricular connection. Surgical considerations. Br Heart $\mathcal{F}$ 1982; 47: 35-40.

20 Freedom RM, Williams WG, Fowler RS, Trusler GA, Rowe RD. Tricuspid atresia, transposition of the great arteries, and banded pulmonary artery. Repair by arterial switch, coronary artery reimplantation, and right atrioventricular valved conduit. $\mathcal{F}$ Thorac Cardiovasc Surg 1980; 80: 621-8.

Requests for reprints to Professor R H Anderson, Cardiothoracic Institute, Fulham Road, London SW3 6HP. 